Gas-Solid Alkali Destruction of Volatile Chlorocarbons

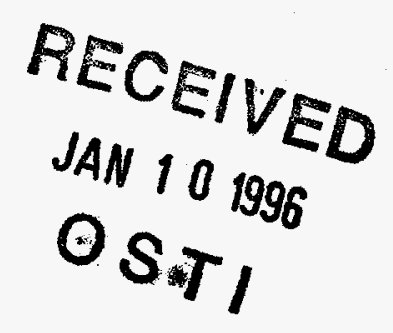

Los Alamos

NATIONAL LABOAATORY

Los Alamos National Laboratory is operated by the University of California for the United States Department of Energy under contract W-7405-ENG-36. 
An Affirmative Action/Equal Opportunity Employer

This report was prepared as an account of work sponsored by an agency of the United States Government. Neither The Regents of the University of California, the United States Government nor any agency thereof, nor any of their employees, makes any warranty, express or implied, or assumes any legal liability or responsibility for the accuracy, completeness, or usefulness of any information, apparatus, product, or process disclosed, or represents that its use would not infringe privately owned rights. Reference herein to any specific commercial product, process, or service by trade name, trademark, manufacturer, or otherwise, does not necessarily constitute or imply its endorsement, recommendation, or favoring by The Regents of the University of California, the United States Government, or any agency thereof. The views and opinions of authors expressed herein do not necessarily state or reflect those of The Regents of the University of California, the United States Government, or any agency thereof. The Los Alamos National Laboratory strongly supports academic freedom and a researcher's right to publish; therefore, the Laboratory as an institution does not endorse the viewpoint of a publication or guarantee its technical correctness. 


\section{DISCLAMMIRR}

Portions of this document may be illegible in electronic image products. Images are produced from the best available original document. 
Gas-Solid Alkali Destruction of

Volatile Chlorocarbons

Jerry Foropoulos, Jr.

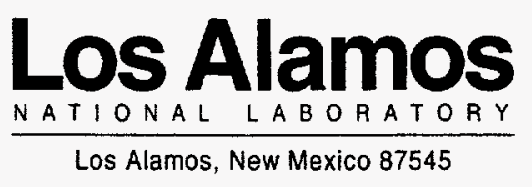




\title{
GAS-SOLID ALKALI DESTRUCTION OF VOLATILE CHLOROCARBONS
}

by

Jerry Foropoulos, Jr.

\begin{abstract}
Many chlorocarbons are environmental dangers and health hazards. The simplest perchlorinated hydrocarbon, carbon tetrachloride, is near the top of the list of hazardous compounds. Carbon tetrachloride was used as a cleaning fluid, solvent, and fire-extinguishing agent. The nuclear and defense complexes also employed great quantities of carbon tetrachloride and other chlorocarbons as cleaning and degreasing agents. Many sites nationwide have underground chlorocarbon contamination plumes. Bulk chlorocarbon inventories at many locations await treatment and disposal. Often the problem is compounded by the chlorocarbon being radioactively contaminated. Waste inventory and groundwater contamination problems exist for many other chlorocarbons, especially methylene chloride, chloroform, and triand tetrachloroethylene.

In this work solid soda lime (a fused mixture of approximately $95 \% \mathrm{CaO}$ and $5 \% \mathrm{NaOH}$ in a coarse, granulated form) at $350^{\circ} \mathrm{C}$ to $400^{\circ} \mathrm{C}$ acts as the hydrolyzing, degradation, and off-gas scrubbing medium. Within soda lime $\mathrm{CO}_{2}$ and $\mathrm{HCl}$ from hydrolysis and degradation convert immediately to calcium and sodium chlorides and carbonates, with water vapor as a volatile byproduct.
\end{abstract}

\section{INTRODUCTION}

Many poly- and perchlorinated hydrocarbons have been known for years as environmental dangers and human health hazards. The simplest perchlorinated hydrocarbon, carbon tetrachloride, is near the top of the list of hazardous compounds. Carbon tetrachloride was commonly used as a cleaning fluid, solvent, and small-scale fireextinguishing agent. The nuclear and defense complexes employed great quantities of carbon tetrachloride as a cleaning and degreasing agent. The legacy is such that many sites have underground contamination plumes which threaten local water tables. Another problem throughout the nation is bulk waste-chlorocarbon inventories. Thousands of kilograms of waste chlorocarbons await disposal or treatment. Often the problem is 
compounded by the waste being contaminated with plutonium and other radioactive species. Similar waste inventory and groundwater contamination problems exist for several other chlorocarbons, especially methylene chloride and tri- and tetrachloroethylene.

In this work soda lime, a highly alkaline solid, is shown to destroy a variety of volatile chlorocarbons. The process is essentially one step, with the addition of water vapor and oxygen as coreactants. The relatively low reaction temperature range, $350^{\circ} \mathrm{C}-400^{\circ} \mathrm{C}$, compared to that of traditional incineration processes, suggests some catalytic activity on behalf of the soda lime. Reaction efficiencies are about $10^{5}$, with potential for significant improvement.

The power of soda lime to destroy chlorocarbons is evident from investigations by others. Smith ${ }^{1}$ reported the destruction of certain chlorocarbons by a column packed with consecutive zones of $\mathrm{Si}$, lime and/or soda lime, and copper oxide. The $\mathrm{Si}$ was heated at $350^{\circ} \mathrm{C}-500^{\circ} \mathrm{C}$, and the lime was heated at $250^{\circ} \mathrm{C}-550^{\circ} \mathrm{C}$. The apparatus was intended to treat waste gases from semiconductor manufacturing. The purpose of the $\mathrm{Si}$ was to react with oxidizing gases, and the lime or soda lime served to destroy the acid gases and halogenated fragments. The copper oxide served to scrub the gas of reductants such as hydrogen and carbon monoxide.

Koper et al. ${ }^{2}$ showed that ultrafine particles of $\mathrm{CaO}$ reacted with $\mathrm{CCl}_{4}$ to yield $\mathrm{CaCl}_{2}$ and $\mathrm{CO}_{2}$. Phosgene was an intermediate product but was avoided if excess $\mathrm{CaO}$ was used. Reactions of $\mathrm{CHCl}_{3}$ yielded $\mathrm{CaCl}_{2}, \mathrm{CO}$, and $\mathrm{H}_{2} \mathrm{O}$, whereas $\mathrm{C}_{2} \mathrm{Cl}_{4}$ yielded $\mathrm{CaCl}_{2}, \mathrm{C}$, and $\mathrm{CaCO}_{3}$. Kinetic parameters demanded that high-surface-area $\mathrm{CaO}$ be used. The observations using soda lime in this work are remarkably similar. Being a coarse, porous material, soda lime has a very high surface area. Phosgene is not a byproduct in my reaction system. In this reference, as well as in my work, the need for an oxidant is shown by the observation of $\mathrm{C}$ and $\mathrm{CO}$.

An example of current methodology to destroy waste chlorocarbons is shown by Katami et al., ${ }^{3}$ who investigated the formation of chlorinated compounds by combustion of waste dry-cleaning materials. Phosgene and $\mathrm{HCl}$ in flue gas were removed by a wet scrubber using $10 \% \mathrm{NaOH}$ solution. Reaction systems such as these rely upon combusting the chlorocarbon in an initial stage and treating the off gas in a subsequent step. Temperatures approaching $900^{\circ} \mathrm{C}$ are needed to ensure complete reaction. The single-stage soda lime system described herein reacts with such compounds at much lower temperatures. Acid gases are never seen.

A key reaction that occurs in the strongly basic environment of soda lime is dehydrohalogenation. Elimination of HF from fluorinated anesthetics to give the corresponding alkenes is described in recent literature (Refs. 4-7). Likewise, in my proposed system $C_{1}$ and $C_{2}$ compounds with adjacent $H$ and $\mathrm{Cl}$ atoms undergo the same 
reaction to give radicals and unsaturated compounds. I postulate that at the surface of soda lime oxygen serves to react with radicals, and unsaturated compounds are formed to give the oxygenated intermediates necessary for a clean overall process.

\section{EXPERIMENTAL}

This process used a gas flow loop with a cylindrical reaction chamber. The reaction chamber had a 12 " by $3 / 4$ " hot zone packed with soda lime. The exposed ends were water cooled. The flow loop had Fourier transform infrared (FTIR) spectroscopy and pressure diagnostics at the exit end of the furnace. Temperature was monitored within the furnace and at the core of the soda lime. The flow loop also had provisions for reagent delivery, along with helium and air supplies. The schematic is shown in Fig. 1.

For each experiment I evacuated the flow loop and entered chlorocarbon vapor into the system until it reached equilibrium. In cases where the vapor pressure was too low for the bellows pump to operate efficiently, I added helium to achieve efficient flow. Circulation was continued for five minutes to mix components. Data sets were as follows: Time, furnace temperature, reactor core temperature, and system pressure.

\section{RESULTS AND OBSERVATIONS}

\section{Carbon Tetrachloride}

Figure 2 shows three spectra of $\mathrm{CCl}_{4}$ reacting with soda lime. Initially, I used approximately 66 torr of $\mathrm{CCl}_{4}$ and 45 torr of carrier gas and let the temperature go straight to $-550^{\circ} \mathrm{C}$. I used the peak at $805 \mathrm{~cm}^{-1}$ to monitor all $\mathrm{CCl}_{4}$ reactions.

The temperature was taken to $\sim 550^{\circ} \mathrm{C}$ to attempt a complete reaction. Because this batch of soda lime was used for three previous runs at or above $500^{\circ} \mathrm{C}$, it contained no entrained water vapor. The lack of water vapor may have accounted for traces of $\mathrm{CCl}_{4}$ remaining after 55 minutes. A pressure decrease was detected well before reaching $550^{\circ} \mathrm{C}$, so the next experiment used fresh soda lime and more frequent IR sampling. 


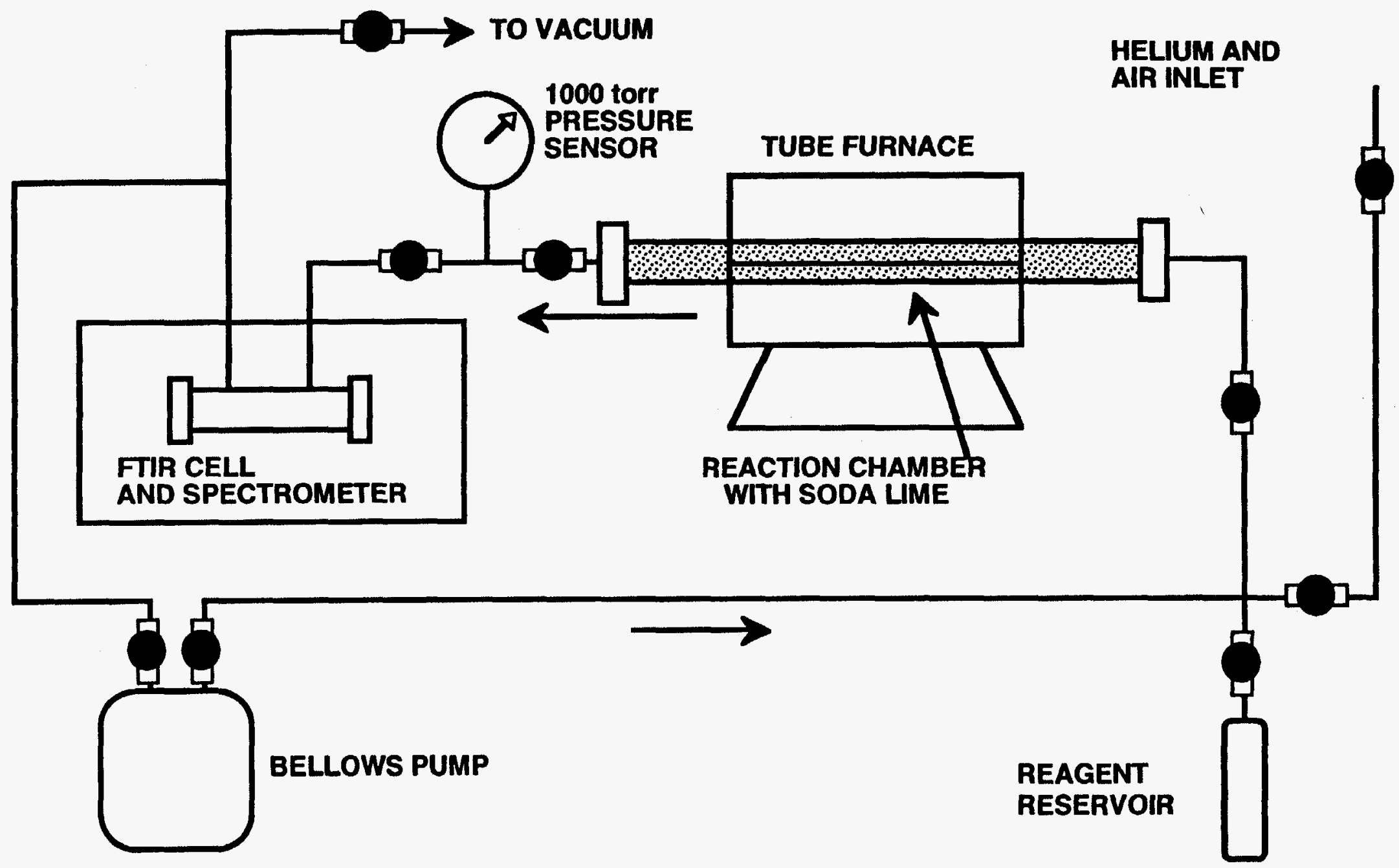

Figure 1. Chlorocarbon destruction flow loop. 

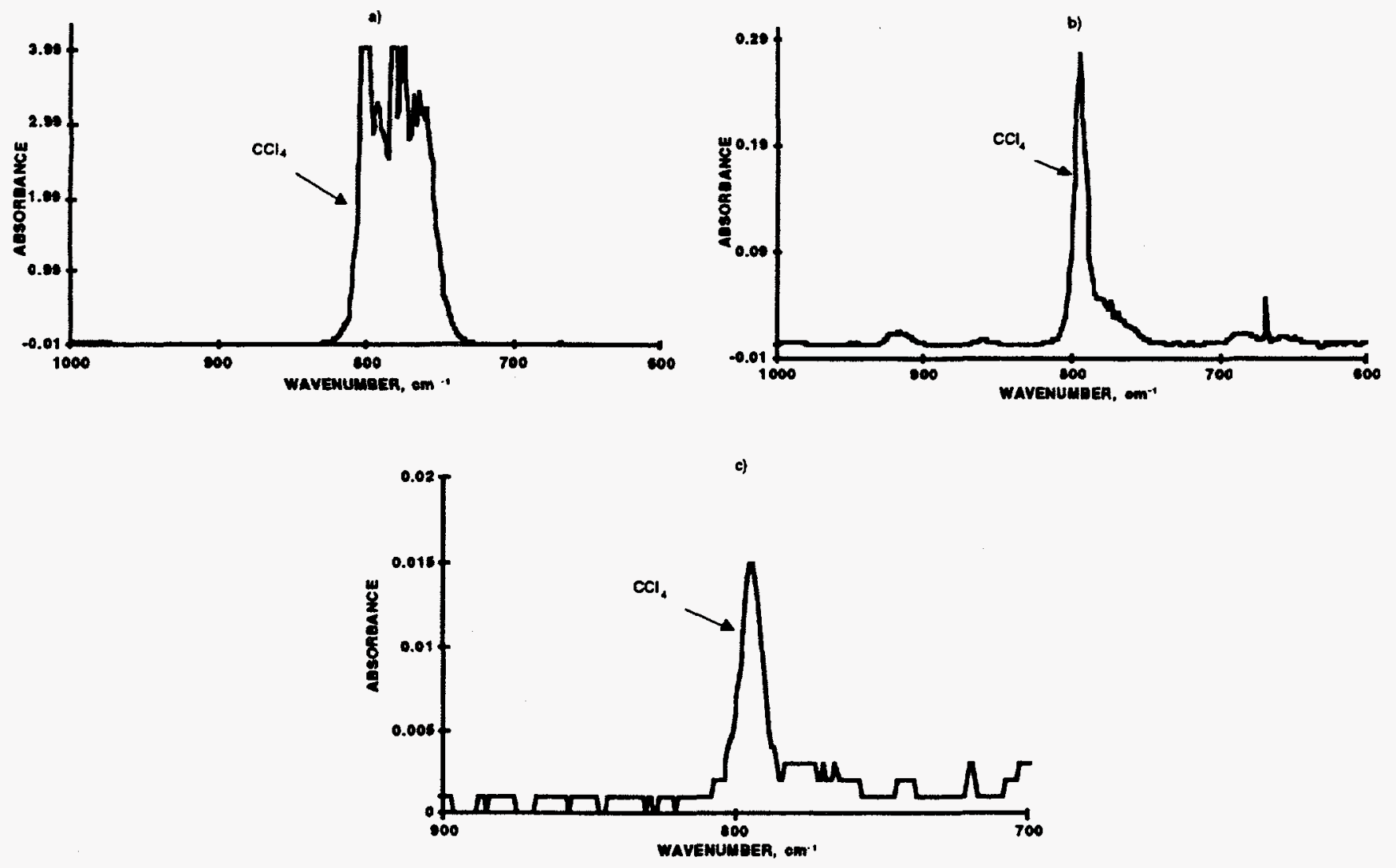

Figure 2. Pressure of 66 torr of $\mathrm{CCl}_{4}$ with soda lime: (a) $85^{\circ} \mathrm{C}, 5$ minutes; (b) $553^{\circ} \mathrm{C}, 25$ minutes; and (c) $554^{\circ} \mathrm{C}, 55$ minutes.

The next experiment used $\sim 350$ torr of helium to improve circulation of the flow loop; the temperature was brought again to $550^{\circ} \mathrm{C}$. Figure 3 shows four spectra of $\mathrm{CCl}_{4}$ reacting with fresh soda lime over approximately one hour.

It is evident from these spectra that soda lime can destroy $\mathrm{CCl}_{4}$ completely. Because I used a flow loop and the entire loop was charged with vapor, the chlorocarbon at the exit end of the tube within the IR cell experienced constant dilution. Therefore, some residual chlorocarbon was detectable after one hour. Each batch of soda lime demonstrated its highest activity when it was fresh and had maximum associated moisture. This supports the need for water vapor in the reaction gases to enhance the destruction of the chlorocarbon species. 

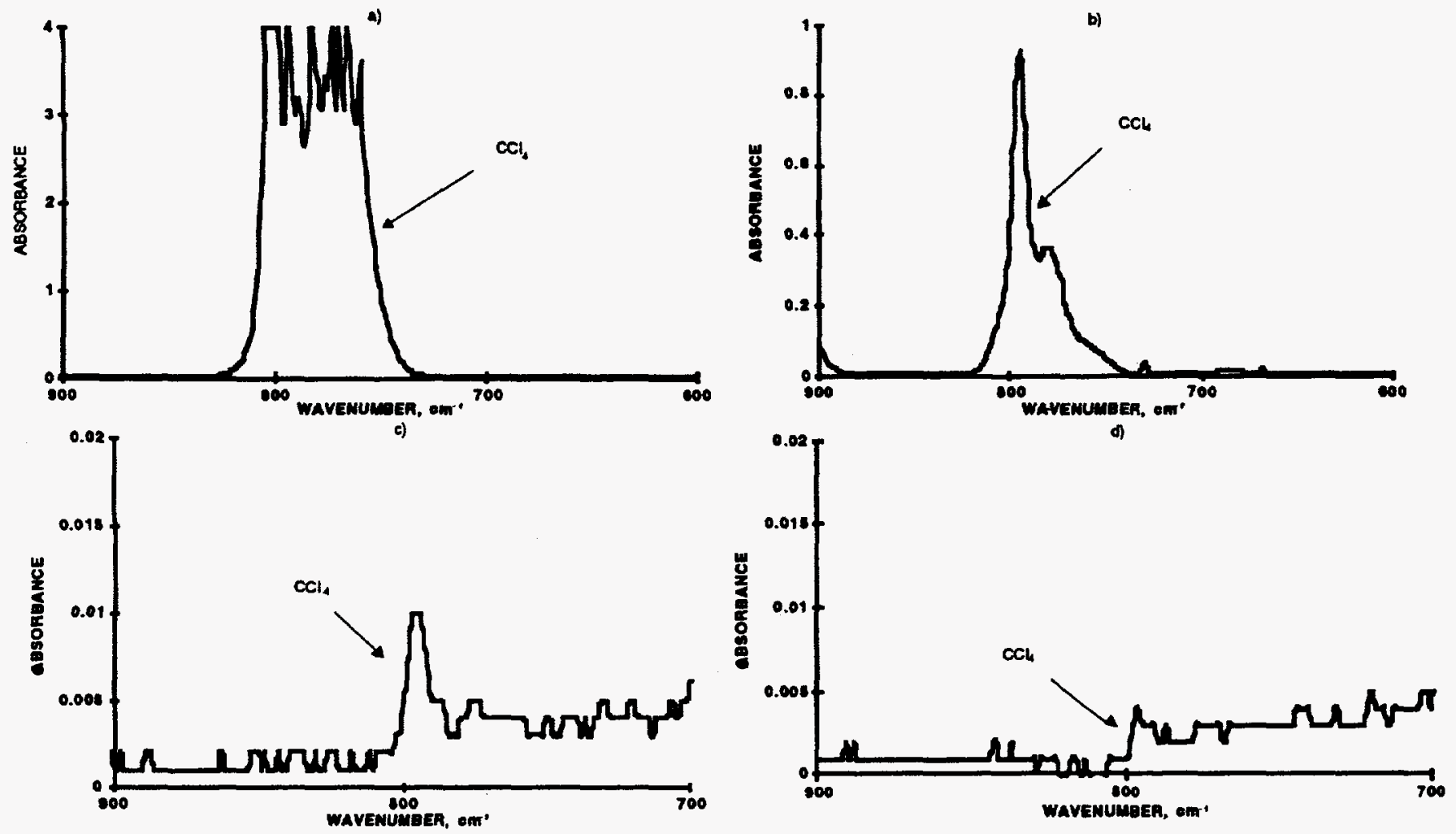

Figure 3. Pressure of 64.6 torr of $\mathrm{CCl}_{4}$ with fresh soda lime, $\sim 550^{\circ} \mathrm{C}$ : (a) 0 minutes, (b) 18 minutes, (c) 40 minutes, and (d) 55 minutes.

Figure 4 relates pressure versus temperature for this experiment. The pitch of the curve before $400^{\circ} \mathrm{C}$ suggests that the reaction initiates well before $400^{\circ} \mathrm{C}$.

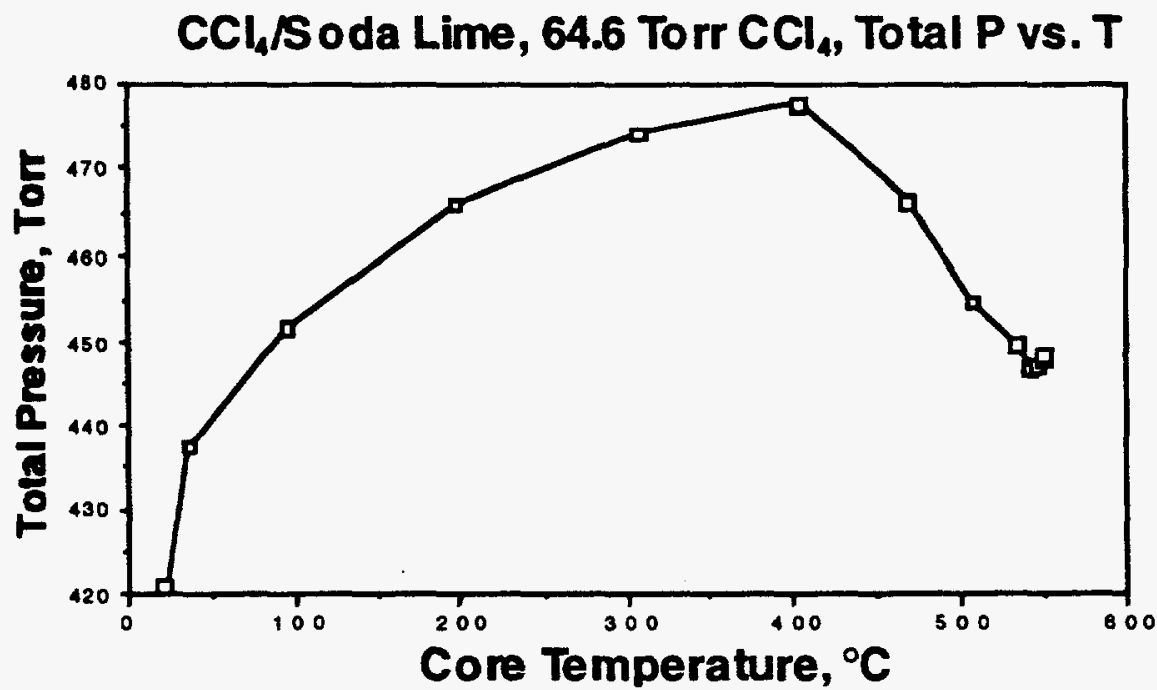

Figure 4. Pressure versus temperature curve for experiment using 64.6 torr of $\mathrm{CCl}_{4}$. 
To understand the reaction below $400^{\circ} \mathrm{C}$, I performed a run using a lower furnace temperature gradient and fresh soda lime and set the furnace to $380^{\circ} \mathrm{C}$. The next three FTIR spectra, shown in Fig. 5, follow the reaction progress.
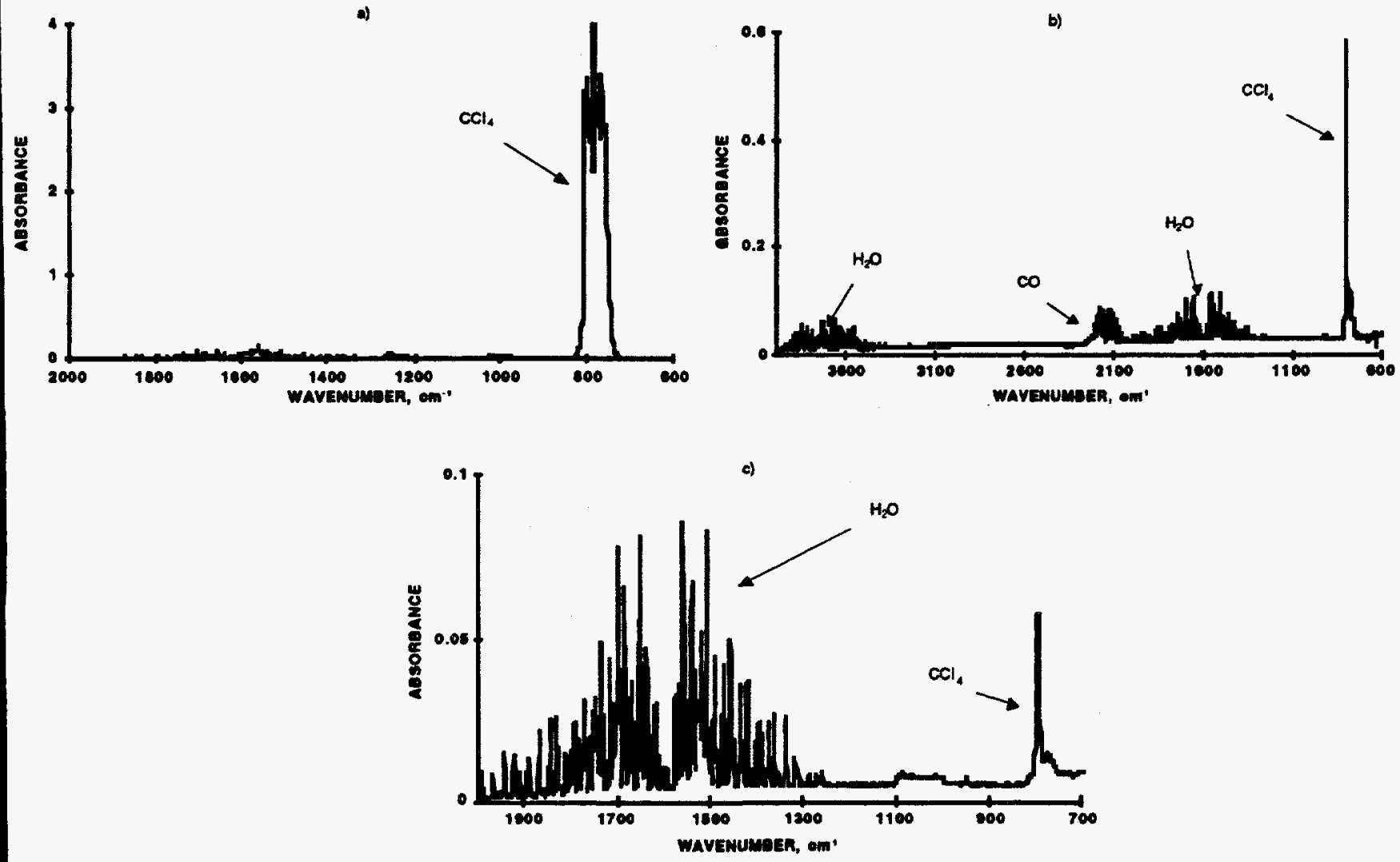

Figure 5. Pressure of 66 torr of $\mathrm{CCl}_{4}$ with fresh soda lime, temperature to $380^{\circ} \mathrm{C}$ : (a) $173^{\circ} \mathrm{C}, 10$ minutes; (b) $332^{\circ} \mathrm{C}, 20$ minutes; and (c) $348^{\circ} \mathrm{C}, 25$ minutes.

Water vapor is evident as multiple bands centered at $\sim 1600$ and $3600 \mathrm{~cm}^{-1}$. The pressure versus temperature curve in this case, shown in Fig. 6, indicates a reaction below $300^{\circ} \mathrm{C}$.

The slope of the curve at $350^{\circ} \mathrm{C}$ is steeply negative. This is where $\mathrm{CCl}_{4}$ reacts at a significant rate. Also, adding additional $\mathrm{CCl}_{4}$ to the gas stream caused rapid disappearance of the water vapor, and the relative reaction rate slowed, reinforcing the need for additional water vapor as a coreactant in future experiments. 


\section{CCl,Soda Lime, 66 Torr $\mathrm{CCl}_{4}$, He Carrier, P vs. T}

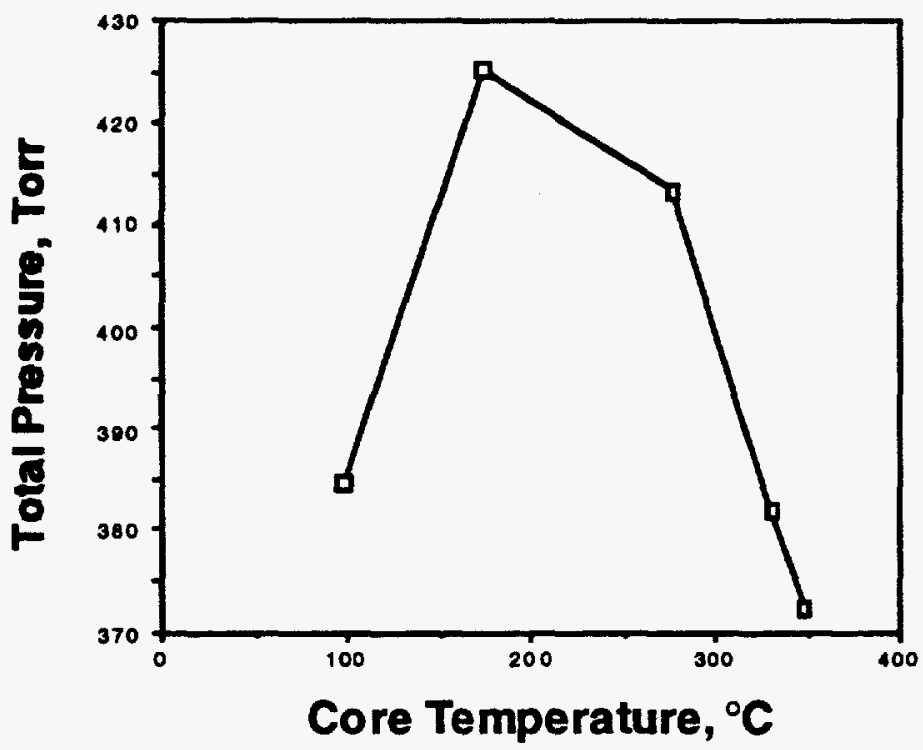

Figure 6. Pressure versus temperature curve for experiment using 66 torr of $\mathrm{CCl}_{4}$.

\section{Methylene Chloride}

Methylene chloride, $\mathrm{CH}_{2} \mathrm{Cl}_{2}$, was of interest not only as a common solvent and groundwater contaminant; it also contains $\mathrm{H}$ and $\mathrm{Cl}$ in proximity. An increased reaction rate relative to $\mathrm{CCl}_{4}$ was expected because of the driving force of dehydrohalogenation. In the first experiment soda lime reacted readily with $\mathrm{CH}_{2} \mathrm{Cl}_{2}$, breaking it down to a carbon species and $\mathrm{HCl}$ that reacted with the soda lime. By adding air to oxidize reducing gases, the reaction proceeded faster than those for $\mathrm{CCl}_{4}$, as shown in the three spectra of Fig. 7.

Using the same batch of soda lime (which was essentially baked to $-300^{\circ} \mathrm{C}$ ), I added neat $\mathrm{CH}_{2} \mathrm{Cl}_{2}$ and set the furnace to $420^{\circ} \mathrm{C}$. This was an attempt to deduce the reducing gas byproducts for this system, as shown in the three spectra of Fig. 8. 

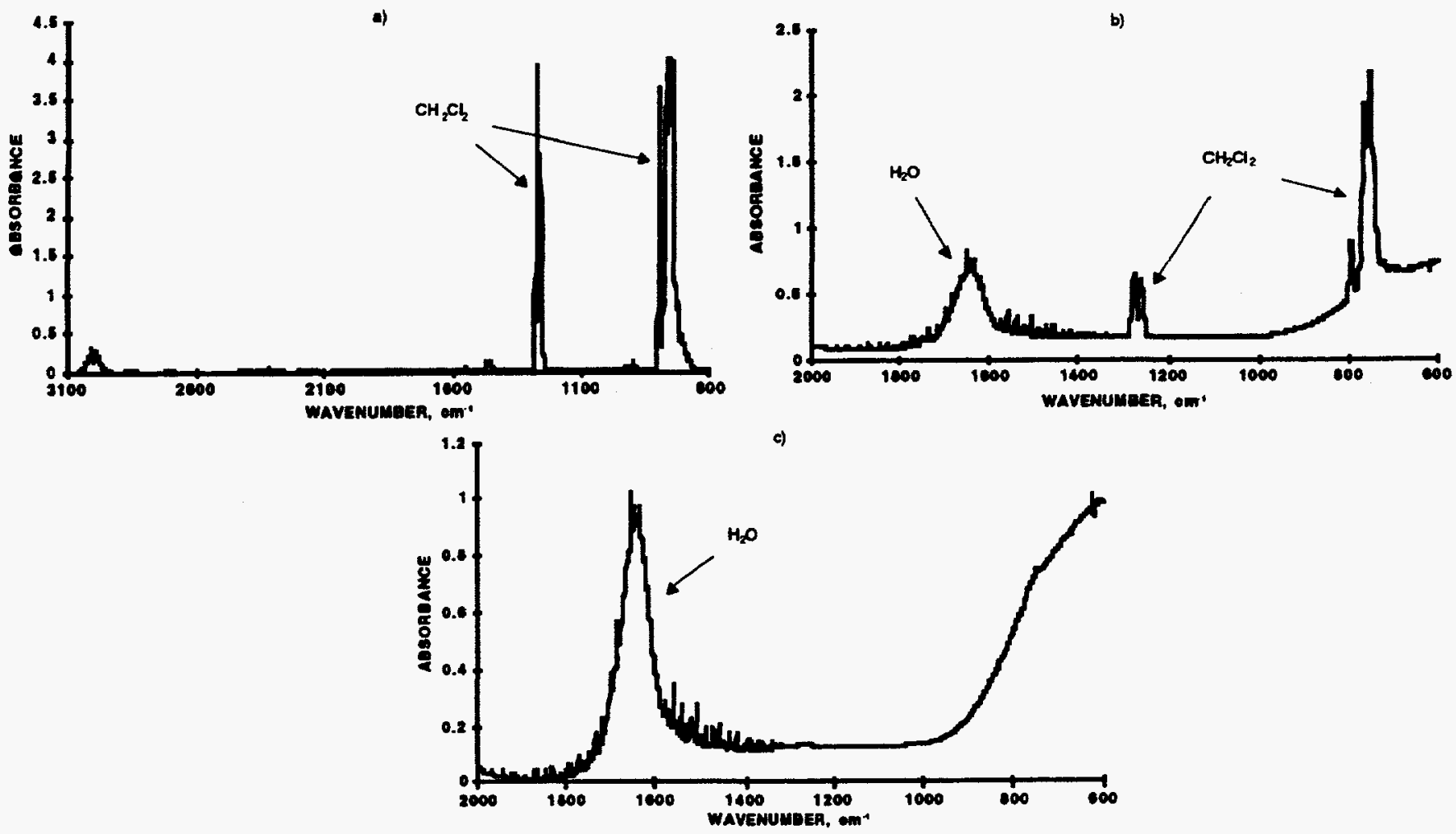

Figure 7. Pressure of 100 torr of methylene chloride with no added air, temperature to $245^{\circ} \mathrm{C}$ : (a) 100 torr, $25^{\circ} \mathrm{C}$; (b) $197^{\circ} \mathrm{C}, 20$ minutes; and (c) $245^{\circ} \mathrm{C}, 25$ minutes.
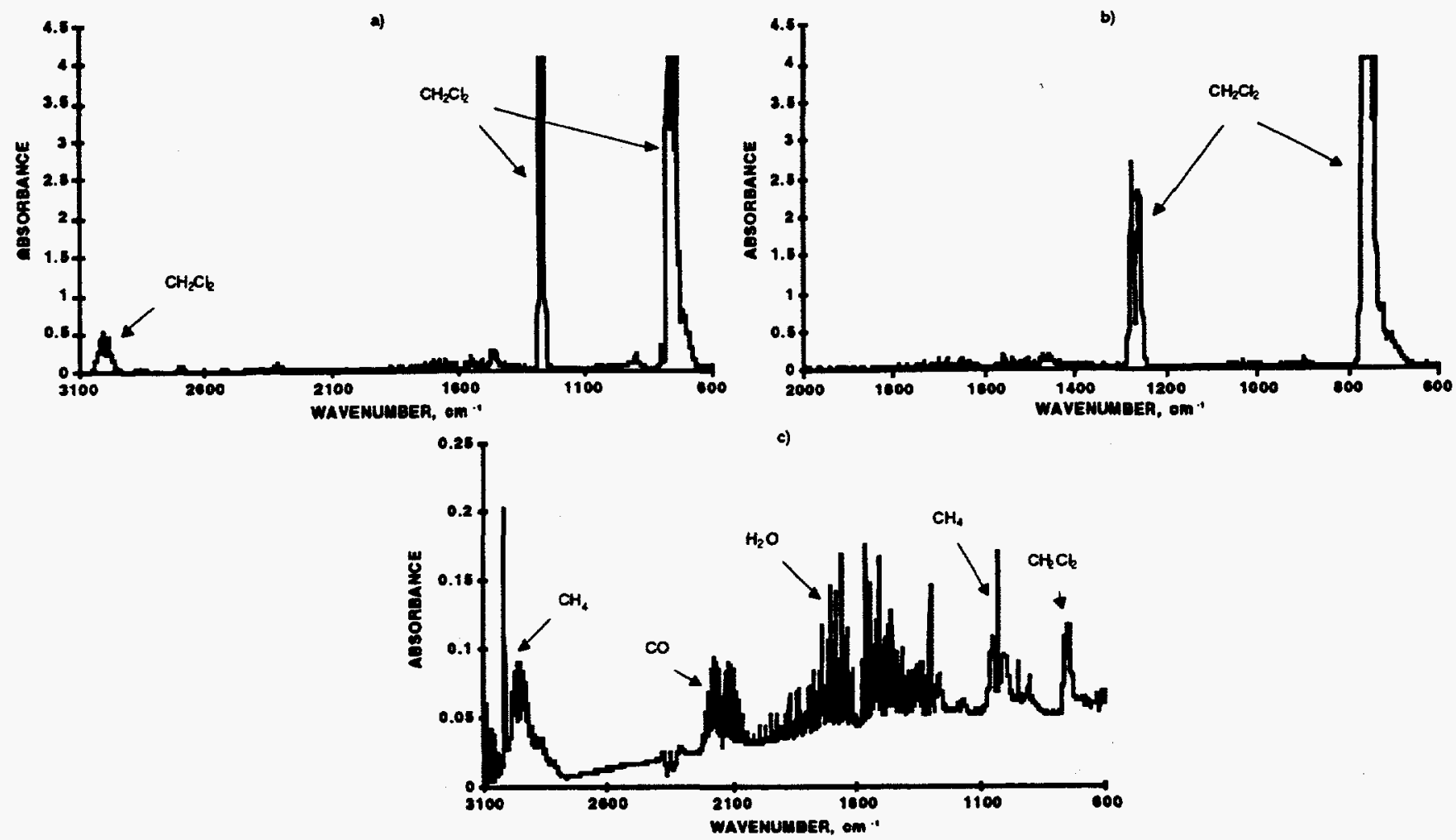

Figure 8. Pressure of 182 torr of methylene chloride, no added air, temperature to $370^{\circ} \mathrm{C}$ : (a) 182 torr, $128^{\circ} \mathrm{C}, 5$ minutes; (b) 210 torr, $265^{\circ} \mathrm{C}, 20$ minutes; and (c) 345 torr, $370^{\circ} \mathrm{C}, 25$ minutes. 
The formation of $\mathrm{CO}$ and $\mathrm{CH}_{4}$ because of the lack of reagent oxygen is apparent; however, they are produced in relatively small amounts. During the entire experiment the total pressure rose from 182 to 392 torr. Subtracting the pressure rise caused only by temperature, the final pressure indicates the formation of a near equimolar amount of gases. The absorbance values of $\mathrm{CH}_{4}$ and $\mathrm{CO}$ do not account for such an increase: I speculate that it is caused by hydrogen. The reaction of $\mathrm{CH}_{2} \mathrm{Cl}_{2}$ with soda lime can be written to account for the formation of hydrogen:

$$
2 \mathrm{NaHCa}_{3} \mathrm{O}_{4}+2 \mathrm{CH}_{2} \mathrm{Cl}_{2} \rightarrow 2 \mathrm{NaCl}+\mathrm{CO}+\mathrm{CaCl}_{2}+\mathrm{CaCO}_{3}+4 \mathrm{CaO}+3 \mathrm{H}_{2}
$$

The presence of methane and water vapor in the final spectrum suggests that side reactions occur. The three spectra in Fig. 9 show the effect of added air towards an initial 70 torr aliquot of methylene chloride.
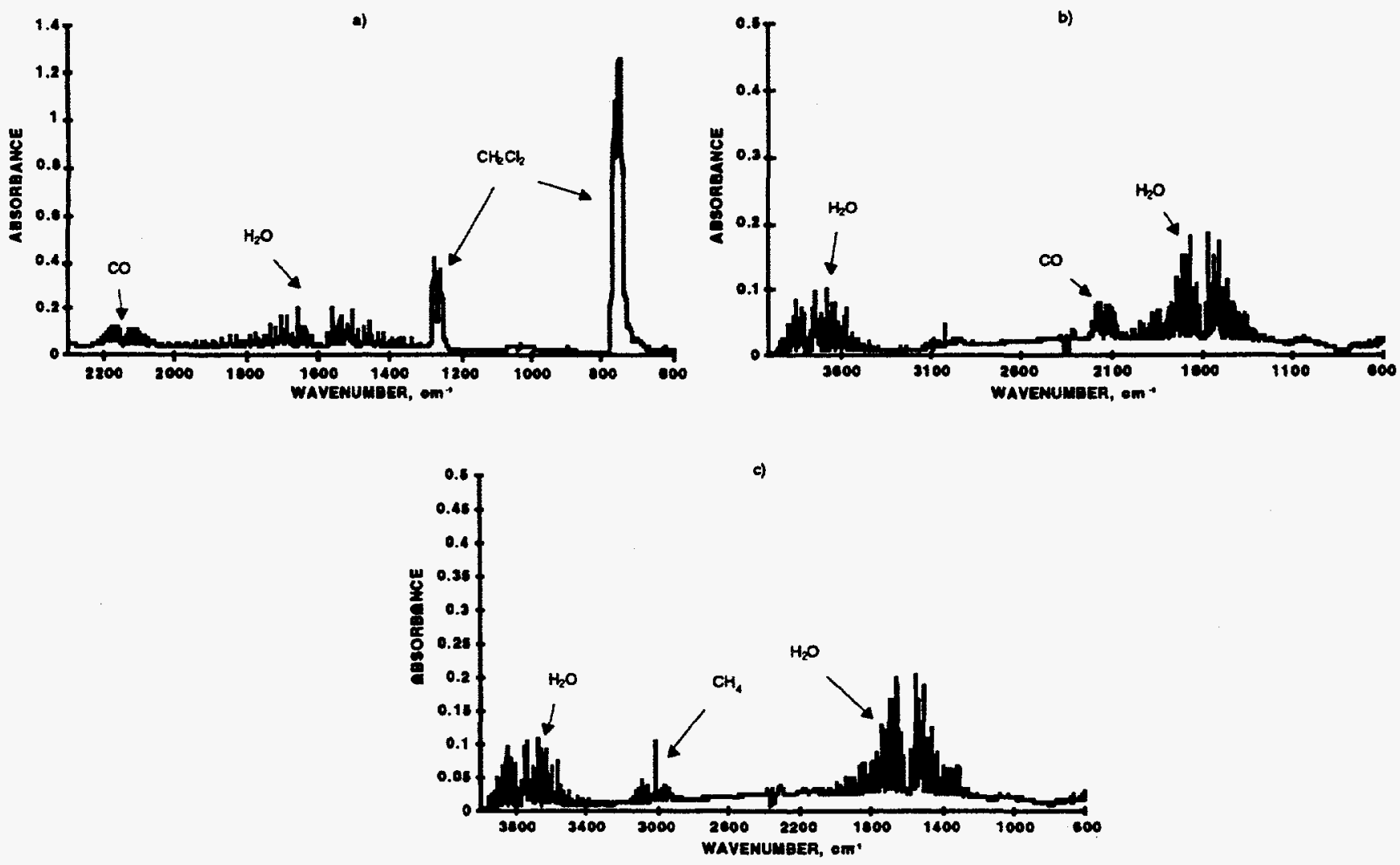

Figure 9. Pressure of 70 torr of methylene chloride with added air, temperature to $396^{\circ} \mathrm{C}$ : (a) $326^{\circ} \mathrm{C}, 20$ minutes; (b) $380^{\circ} \mathrm{C}, 25$ minutes; and (c) $396^{\circ} \mathrm{C}, 35$ minutes. 
The addition of oxygen prevents formation and accumulation of reducing and potentially flammable gases. In this case the overall pressure decreased from 447 to 415 torr in the temperature range of $41^{\circ} \mathrm{C}$ to $390^{\circ} \mathrm{C}$. Note that $\mathrm{CO}$ is virtually eliminated.

\section{Chloroform}

With chloroform the reaction favors the formation of $\mathrm{CO}$ almost exclusively. The three IR spectra in Fig. 10 show a final $\mathrm{CO}$ absorbance well over 1. When I added air the formation of $\mathrm{CO}$ was suppressed to $20 \%$ of the previous value, as shown in the three spectra in Fig. 11. Obviously, a higher oxygen percentage would totally suppress $\mathrm{CO}$ formation. Carbon dioxide is almost never seen because of the formation of calcium carbonate.
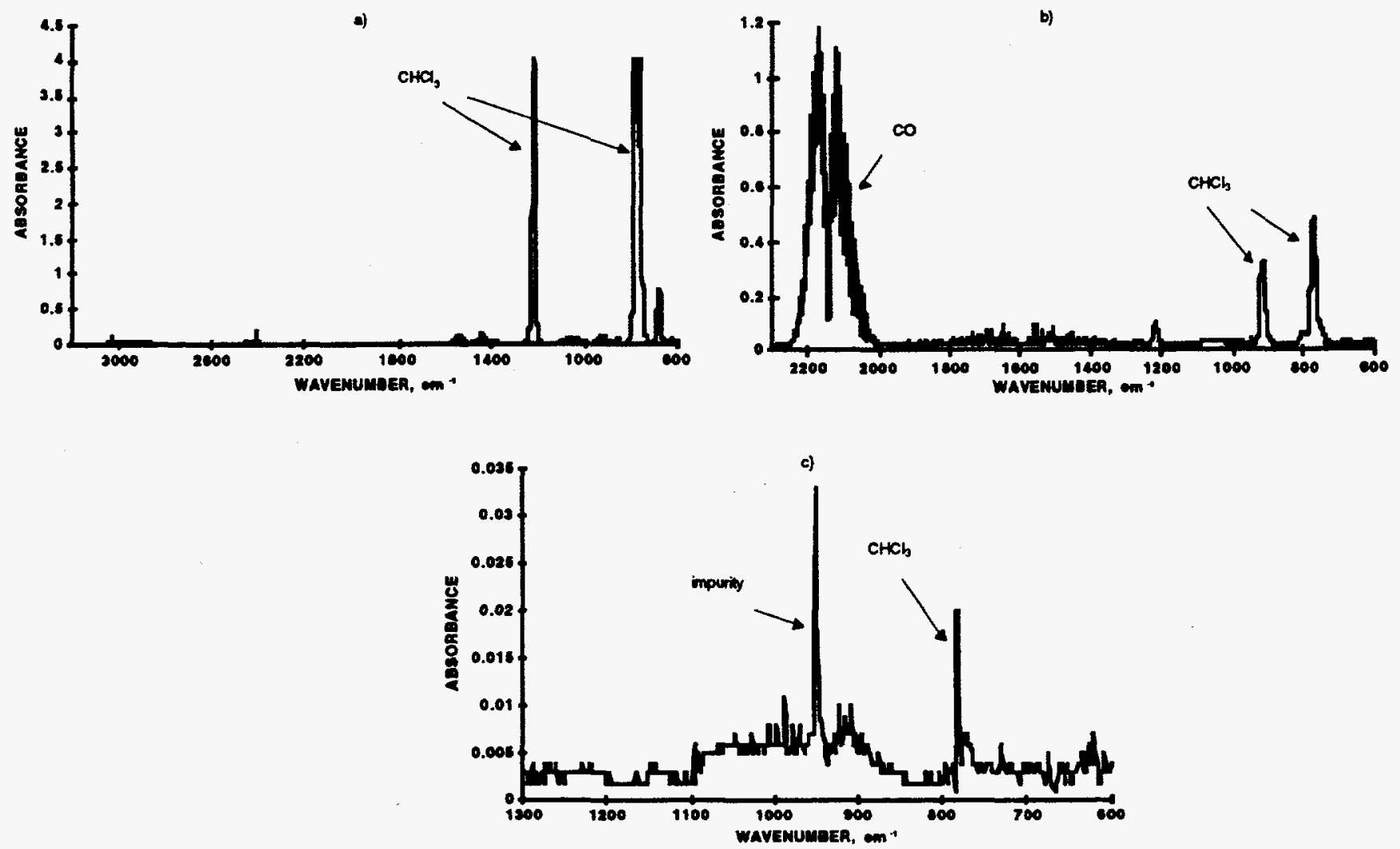

Figure 10. Pressure of 107 torr of chloroform with no added air, temperature to $354^{\circ} \mathrm{C}$ : (a) 0 minutes, (b) 30 minutes, and (c) 40 minutes. 

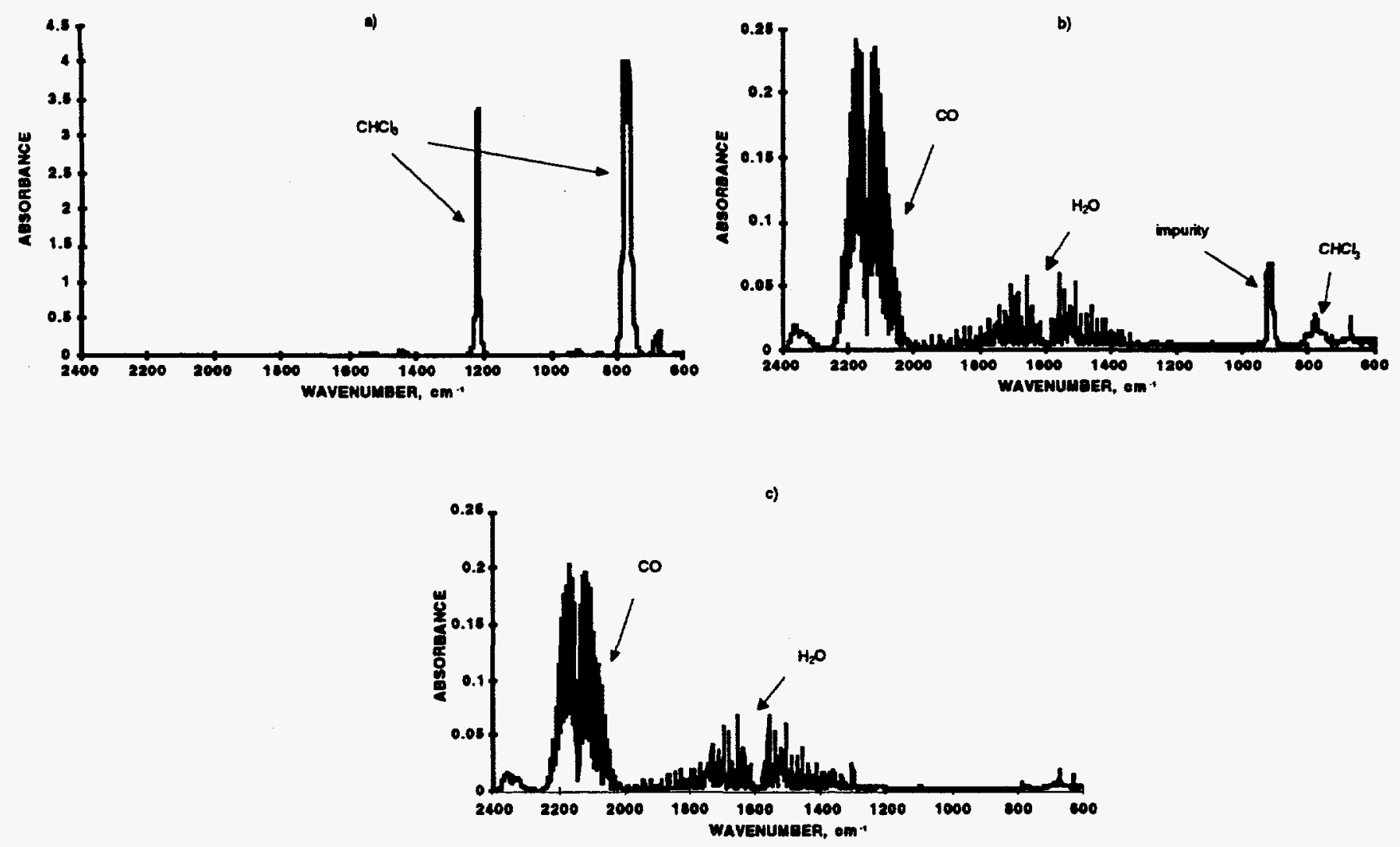

Figure 11. Pressure of 50 torr of chloroform with added air, temperature to $393^{\circ} \mathrm{C}$ : (a) 0 minutes, (b) 25 minutes, and $(c) 35$ minutes.

\section{Trichloroethylene and Tetrachloroethylene}

Results for trichloroethylene and tetrachloroethylene were similar to the above examples. Both reacted completely at $400^{\circ} \mathrm{C}$ and needed oxygen and water vapor to effect complete reaction without forming $\mathrm{CO}$ or carbon.

\section{DISCUSSION}

Using a basic oxide mixture such as soda lime to destroy chlorocarbons relates to the ability of compounds like $\mathrm{CCl}_{4}$ to chlorinate oxides. The action of $\mathrm{CCl}_{4}$ on oxides is thermodynamically favored because of the formation of $\mathrm{CO}_{2}$. The initial step of oxide chlorination by $\mathrm{CCl}_{4}$ is represented by the dissociation of $\mathrm{CCl}_{4}$ into chlorine atoms and dichlorocarbene. Dichlorocarbene scavenges oxygen and forms carbonyl chloride readily. However, carbonyl chloride is itself a good chlorinating agent and is rarely seen in continuous loop systems in more than trace quantities. For most gas-solid reactions of $\mathrm{CCl}_{4}$, the optimum temperature is more than $600^{\circ} \mathrm{C}$. Potentially, any perchlorocarbon can react with most metal oxides to give metal chlorides and carbon oxides. 


\section{Background Chemistry}

Whereas $\mathrm{CCl}_{4}$ requires relatively high temperatures for efficient reaction with most metal oxides, the first carbon-chlorine bond can react under significantly milder conditions. One way to achieve this is to react $\mathrm{CCl}_{4}$ with a highly basic oxide or hydroxide. Using the hydroxide ion as an example, advanced organic chemistry texts describe hydrolysis of aliphatic chlorides by $\mathrm{OH}^{-}$:

$$
\mathrm{R}-\mathrm{Cl}+\mathrm{OH}^{-} \rightarrow \mathrm{R}-\mathrm{OH}+\mathrm{Cl}^{-}
$$

Upon attack of the hydroxide ion on the carbon atom adjacent to chlorine, a carbonoxygen bond forms simultaneously as the chloride ion leaves. The facility of this reaction depends on the degree of polarity of the carbon-chlorine bond. The greater the polarity, the easier and faster the reaction will proceed. Conversely, this phenomenon determines the acidic character of the carbon center. The more electron-deficient (acidic) the carbon atom, the more reactive it is towards hydroxide. An example is the difference in reactivity of $\mathrm{RCH}_{2} \mathrm{Cl}$ versus $\mathrm{RC}(\mathrm{O}) \mathrm{Cl}$. The former requires a strong base such as $\mathrm{NaOH}$ to form the alcohol, while the latter needs only a weak base such as $\mathrm{H}_{2} \mathrm{O}$ to form the corresponding carboxylic acid.

Carbon tetrachloride is also susceptible to hydrolysis, even by water at elevated temperature:

$$
\mathrm{CCl}_{4}+\mathrm{H}_{2} \mathrm{O} \rightarrow \mathrm{CCl}_{3} \mathrm{OH}^{\prime}+\mathrm{HCl}
$$

After each attack by water, the carbonaceous products are highly unstable and lose $\mathrm{HCl}$ instantaneously, ultimately leaving carbon dioxide and hydrogen chloride. The overall reaction is as follows:

$$
\mathrm{CCl}_{4}+2 \mathrm{H}_{2} \mathrm{O} \rightarrow \mathrm{CO}_{2}+4 \mathrm{HCl}
$$

In the gas phase at $25^{\circ} \mathrm{C}$, the free energy of reaction is $-61.6 \mathrm{kcal} / \mathrm{mole}$ of $\mathrm{CCl}_{4}$. It follows that if we incorporate a chemical sink for $\mathrm{HCl}$ and $\mathrm{CO}_{2}$ into this reaction, we have a basis for the complete and irreversible destruction of carbon tetrachloride. In this work solid soda lime (a strong base) replaces water in the hydrolysis reaction. Soda lime is a mixture of approximately $80 \%-95 \%$ calcium oxide and $5 \%-20 \%$ sodium hydroxide in a coarse, granulated form. Within this highly alkaline environment, $\mathrm{CO}_{2}$ and $\mathrm{HCl}$ do not exist. They convert immediately to calcium and sodium chlorides and carbonates. Therefore, to use soda lime as a reaction medium and gas scrubber provides a route to digest carbon 
tetrachloride to produce a solid, nonhazardous byproduct.

Expanding the scope of the $\mathrm{CCl}_{4}$ reaction to other volatile chlorocarbons, the premise for reactivity towards soda lime is like that for $\mathrm{CCl}_{4}$, save for a property I will call "oxidative deficiency". Returning to the $\mathrm{CCl}_{4}$ reaction with soda lime, the overall mass balance equation completely consumes $\mathrm{CCl}_{4}$ with no off gas that is either oxidizing or reducing. If we substitute a compound such as $\mathrm{CH}_{2} \mathrm{Cl}_{2}$ for $\mathrm{CCl}_{4}$, the mass balance equation contains either excess hydrogen or partially oxidized carbon (best represented as carbon monoxide). We solve this chemical dilemma by adding oxygen to the reactants to convert any $\mathrm{H}_{2}$ and $\mathrm{CO}$ to $\mathrm{H}_{2} \mathrm{O}$ and $\mathrm{CO}_{2}$ in situ. If a chlorocarbon contains hydrogen or carboncarbon bonds of any kind, it is "oxidatively deficient" and requires oxygen to react with soda lime to produce halides, carbonates, and water exclusively. This is done by adding ordinary air or oxygen with the chlorocarbon.

\section{SUMMARY}

This process to convert chlorocarbons has distinct advantages over competing technologies. Adsorption onto activated carbon may efficiently separate chlorocarbons from water, but there is still the task of desorption and treatment. Excess water vapor in the soda lime system does not affect its capacity to destroy chlorocarbons, therefore the unseparated vapors may be put through the system without degradation of the solid reagent.

Operating temperatures within the soda lime are at or below $400^{\circ} \mathrm{C}$; thus this system is in the range of thermal catalytic oxidation processes, yet does not have drawbacks such as catalyst poisoning. Nor is a secondary scrubber system required for products such as $\mathrm{HCl}$.

Photolytic and plasma-based technologies are efficient towards destruction of the original chlorocarbon species, but the reactions are nonspecific and often produce other toxic products. A secondary scrubber is necessary to handle the off gases.

Benefits of using soda lime to destroy various chlorocarbons are summarized below:

1. The end product is a mixture of benign, nonhazardous salts ( $\mathrm{Ca}$ and $\mathrm{Na}$ chlorides and carbonates). By itself this benefit has a tremendous impact on waste minimization.

2. The reagent soda lime is inexpensive and available in bulk quantities. It retains its structural integrity despite large amounts of water vapor.

3. This method unitizes a reactor and an off-gas scrubber. Chlorocarbons and acid gas byproducts simultaneously react within the soda lime chamber. The reactor may be easily sized and configured to accommodate a wide range of throughput levels. 
4. Reaction thresholds are below $400^{\circ} \mathrm{C}$. Unlike standard incineration processes in which temperatures exceed $600^{\circ} \mathrm{C}$, followed by gas scrubbing, this process uses relatively low temperatures. In trial experiments reactions of certain chlorocarbons were evident at temperatures as low as $250^{\circ} \mathrm{C}$, increasing to a substantial rate by $350^{\circ} \mathrm{C}$. An explanation is the possible catalytic activity of soda lime.

5. Potential reaction efficiencies are $10^{6}$. Using a flow loop, relative chlorocarbon concentrations were measured in millitorr of pressure. Initial pressures were tens of torr. Fine-tuning parameters plus water vapor and oxygen addition can achieve "six nines" reaction efficiency.

6. The only additives are oxygen and water vapor. Oxygen converts reducing gases to carbon dioxide and water vapor within the reactor. Water vapor assists reactions.

7. This process can apply to chlorocarbons from other sources. Filtration and thermal desorption systems can separate chlorocarbon vapors from solids, particulates, and nonvolatile liquids. This benefits situations where chlorocarbons exist with solid waste, oils, radioactive particulates, and nonvolatile matrices.

\section{REFERENCES}

1. Smith, James R., "Dry Waste Gas Cleaning," Intl. Patent Appl. No. 8,911,905, 1989.

2. Koper, Olga; Li, Yong Xi; Klabunde, Kenneth J., "Destructive Adsorption of Chlorinated Hydrocarbons on Ultrafine (Nanoscale) Particles of Calcium Oxide," Chem. Mater., 1993, 5(4), 500-5.

3. Katami, Takeo; Nisikawa, Harumitsu; Yasuhara, Akio, "Emission of Chlorinated Compounds by Combustion of Waste Dry-Cleaning Materials," Chemosphere, 1992, 24(3), 343-9.

4. Morio, Michio; Fujii, Kohyu; Satoh, Nobukatsu; Imai, Masahiro; Kawakami, Urao; Mizuno, Takahiro; Kawai, Yoichiro; Ogasawara, Yasumasa; Tamura Takashi; et al., "Reaction of Sevoflurane and its Degradation Products with Soda Lime. Toxicity of the Byproducts," Anesthesiology, 1992, 77(6), 1155-64. 
5. Eger II, Edmond I.; Strum, David P., "The Absorption and Degradation of Isoflurane and I-653 by Dry Soda Lime at Various Temperatures," Anesth., Analg., 1987, 66(12), 131215.

6. Strum, David P.; Johnson, Brynte H.; Eger, Edmond I., II, "Stability of Sevoflurane in Soda Lime," Anesthesiology, 1987, 67(5), 779-81.

7. Harden, J. M.; Ramsey, G. G., "Catalytic Dehydrohalogenation: A Chemical Destruction Method for Halogenated Organics," Report, EPA/600/2-86/113; 1986. 